\title{
PENGARUH GAYA KEPEMIPINAN, BUDAYA ORGANISASI DAN STRES KERJA TERHADAP KINERJA KARYAWAN \\ (Studi Kausal di Layanan Social Media TelkomCare Telkom Indonesia Jakarta)
}

\author{
Ria Cendana Ardhiyaningtyas dan Ahmad Faisal \\ Mahasiswa dan Dosen MM Unsurya \\ riaardhiy@gmail.com dan afaisal@universitassuryadarma.ac.id
}

\begin{abstract}
This study aims to obtain empirical data, facts, and valid and correct information, and can be trusted, about Leadership Style, Organizational Culture and Work Stress on Employee Performance. Using a quantitative research approach and the survey method. To prove the influence of the variables of Leadership Style, Organizational Culture and Job Stress on Performance in this study, data analysis techniques were carried out with Path Analysis. Based on the results of the research analysis:

There is a positive and significant direct effect of the Leadership Style variable on Job Stress. There is a positive and significant direct effect of the Organizational Culture variable on Job Stress. There is a positive and significant direct effect of the Leadership Style variable on Performance. There is a positive and significant direct effect of the Organizational Culture variable on the Performance variable. There is a positive and significant direct effect of the Job Stress variable on the Performance variable.
\end{abstract}

Keywords: Leadership Style, Organizational Culture, Job Stress and Performance

\section{PENDAHULUAN}

Sumber daya manusia merupakan aset terpenting perusahaan karena perannya sebagai subyek pelaksana kebijakan dan kegiatan operasional perusahaan. Agar perusahaan tetap eksis maka harus berani menghadapi tantangan dan implikasinya yaitu menghadapi perubahan dan memenangkan persaingan.

Dalam mewujudkan pencapaian tujuan organisasi banyak unsur-unsur yang menjadi hal penting dalam pemenuhannya, diantaranya adalah kepemimpinan. Sumber daya manusia yang telah tersedia jika tidak dikelola dengan baik maka tidak akan memperoleh tujuan yang telah direncanakan, sehingga peranan pemimpin sangat penting yang dapat mempergunakan wewenang dan kepemimpinan untuk mencapai suatu tujuan. Kepemimpinan merupakan gaya seorang pemimpin mempengaruhi bawahannya agar mau bekerja sama dan bekerja efektif.

Kinerja karyawan dipengaruhi oleh gaya kepemimpinan. Hubungan antara pemimpin (leader) dengan yang di pimpin (follower) dan bagaimana seorang pemimpin mengarahkan follower akan menentukan sejauh mana follower mencapai tujuan atau harapan pimpinan.

Tuntuan pekerjaan serta budaya organisasi yang kurang menyenangkan terkadang mempunyai dampak bagi tingkat stress karyawan. maka seorang pemimpin akan dapat memberikan bimbingan, dorongan serta motivasi kepada seluruh anggotanya untuk mencapai tujuan. Jika dalam proses interaksi tersebut berhasil dengan baik, maka ia akan mampu memberikan kinerja yang baik sekaligus dapat meningkatkan kinerjanya. 
Budaya organisasi dapat menjadi basis adaptasi dan kunci keberhasilan organisasi yang bisa memberikan kontribusi besar bagi keberhasilan organisasi.

Besar kecilnya kinerja dipengaruhi oleh tinggi rendahnya stress kerja yang dipengaruhi oleh kinerja dan beban kerja. Berdasarkan uraian diatas, maka peneliti tertarik untuk meneliti pengaruh gaya kepemimpina, budaya orgnanisasi dan stres kerja terhadap kinerja karyawan social media Telkom Care di PT Telkom Indonesia

\section{RUMUSAN MASALAH}

Agar pembatasan masalah tersebut lebih operasional dan dapat dibuktikan melalui pembuktian hipotesis penelitian, maka penulis dalam penelitian ini merumuskan sebagai berikut :

1. Apakah terdapat pengaruh Gaya Kepemimpinan terhadap Stres Kerja Karyawan Layanan Social Media Telkom Care PT. Telkom Indonesia?

2. Apakah terdapat pengaruh Budaya Organisasi terhadap Stres Kerja Karyawan Layanan Social Media Telkom Care PT. Telkom Indonesia?

3. Apakah terdapat pengaruh Gaya Kepemimpinan terhadap Kinerja Karyawan Layanan Social Media Telkom Care PT. Telkom Indonesia?

4. Apakah terdapat pengaruh Budaya Organisasi terhadap Kinerja Karyawan Layanan Social Media Telkom Care PT. Telkom Indonesia?
5. Apakah terdapat pengaruh Stres terhadap Kinerja Karyawan Layanan Social Media Telkom Care PT. Telkom Indonesia ?

\section{TINJAUAN TEORI}

\section{Kinerja}

Pemangku negara mengungkapkan bahwa kinerja adalah hasil kerja secara kualitas dan kuantitas yang dicapai oleh pegawai dalam melaksanakan tugasnya sesuai dengan tanggung jawab yang diberikan kepadanya Kinerja merupakan tolak ukur dalam menentukan keberhasilan para pemimpin dalam mengelola organisasi. Kinerja yang baik di tunjukan dengan kualitas dan kuantitas seperti yang diharapkan berdasarkan tugas dan tanggung jawab masing-masing. Kualitas yang dimaksud disini adalah dilihat dari kehalusan, kebersihan dan ketelitian dalam pekerjaan sedangkan kuantitas dilihat dari jumlah atau banyaknya pekerjaan yang harus diselesaikan karyawan.

Menurut ut Alisjahbana (2012) Kinerja adalah ekspresi potensi berupa perilaku atau cara seseorang/ kelompok orang dalam melaksanakan suatu kegiatan atau tugas sehingga menghasilkan suatu produk yang merupakan wujud dari semua tugas dan tanggung jawab pekerjaan yang diberikan kepadanya

Berdasarkan uraian di atas dapat disintesiskan bahwa kinerja sebagai hasil kerja yang dapat dicapai oleh seseorang atau sekelompok orang dalam suatu organisasi baik secara kuantitatif maupun kualitatif sesuai 
dengan kewenangan dan tugas tanggung jawab masi-masing, dalam upaya mencapai tujuan organisasi bersangkutan secara legal, tidak melanggar hukum dan sesuai dengan moral maupun etika dan merupakan dari fungsi interaksi antara kemampuan (ability), motivasi (motivation), dan kesempatan (opportunity). Untuk mencapai kinerja yang baik seseorang dapat dilihat dengan indikator (1) Quality $O f$, (2) Quantity of work, (3) Job knowledge, (4) Creativeness, (5) Cooperative, (6) Initiative, (7) Dependability, (8) Personal Quality.

\section{Gaya Kepemimpinan}

Menurut Sarros dan Butchatsky leadership is defined as the purposeful behaviuor of influencing others to contribute to a commonly agreed goal for the benefit of individual as well as the organization or common good (kepemimpinan didefinisikan sebagai perilaku bertujuan mempengaruhi orang lain untuk berkontribusi pada tujuan yang disepakati bersama untuk kepentingan individu maupun organisasi atau kebaikan bersama).

Hersey dan Blanchart, kepemimpinan adalah setiap upaya seorang yang mencoba untuk mempengaruhi tingkah laku seorang atau kelompok, upaya untuk mempengaruhi tingkah laku ini bertujuan mencapai tujuan perorangan, tujuan teman, atau tujuan bersama sama dengan tujuan organisasi yang mungkin sama atau berbeda.

Untuk mencapai kemampuannya kepemimpinan seseorang dapat dilihat dengan indikator (1) Cara berkomunikasi,
Pemberian motivasi, (3) faktor internal tubuh. (3) Kemampuan memimpin, (4) Pengambilan keputusan, (5) Kekuasaan yang positif.

\section{Budaya Organisasi}

Budaya organisasi akan menentukan apa yang boleh dan tidak boleh dilakukan oleh para anggota organisasi; menentukan batasbatas normatif perilaku anggota organisasi; menentukan sifat dan bentuk-bentuk pengendalian dan pengawasan organisasi; menentukan gaya manajerial yang dapat diterima oleh para anggota organisasi; menentukan cara-cara kerja yang tepat, dan sebagainya. Secara spesifik peran penting yang dimainkan oleh budaya organisasi (birokrasi) adalah membantu menciptakan rasa memiliki terhadap organisasi; menciptakan jati diri para anggota organisasi; menciptakan keterikatan emosional antara organisasi dan pekerja yang terlibat didalamnya; membantu menciptakan stabilitas organisasi sebagai sistem sosial; dan menemukan pola pedoman perilaku sebagai hasil dari norma-norma kebiasaan yang terbentuk dalam keseharian.

Berdasarkan uraian di atas dapat disintesiskan bahwa budaya organisasi merupakan pola asumsi dasar bersama yang dipelajari oleh kelompok dalam suatu organisasi sebagai alat untuk memecahkan masalah terhadap penyesuaian faktor eksternal dan integrasi faktor internal, dan telah terbukti sah, menjadi sebuah sistem yang memiliki kebersamaan pengertian. Untuk melihat budaya organisasi yang ideal dapat dilihat dengan 
indikator : 1.Inisiatif, 2.Toleransi terhadap Tindakan Beresiko, 3. Pengarahan, 4. Integrasi, 5. Dukungan Manajemen, 6.Kontrol, 7. Identitas, 8. sistem imbalan , 9. Toleransi terhadap Konflik, 10. Pola komunikasi :

\section{Stres Kerja}

Stres bukan sesuatu yang sudah ada pada diri seseorang melainkan suatu proses seseorang dalam interaksinya dengan orang lain dan berhubungan dengan lingkungan sosial dan budaya.

Dampak stres kerja dapat menguntungkan atau merugikan karyawan. Dampak yang menguntungkan diharapkan akan memacu karyawan untuk dapat menyelesaikan pekerjaan dengan bersemangat sebaik-baiknya, namun jika stres tidak mampu diatasi maka akan menimbulkan dampak yang merugikan karyawan.

Seseorang yang mengalami stres akan kesulitan dalam berkonsentrasi dan mengoptimalkan kemampuannya.
Stres yang tidak diatasi dengan baik biasanya berakibat pada ketidakmampuan seseorang berinteraksi secara positif dilingkungan baik itu dilingkungan pekerjaannya maupun dilingkungan luarnya. Biasanya stres semakin kuat apabila seseorang menghadapi masalah yang datang tanpa henti. Menjadikan Stres merupakan kondisi ketegangan yang berpengaruh terhadap emosi , jalan pikiran dan kondisi fisik seseorang.

Berdasarkan uraian di atas dapat disintesiskan bahwa stres adalah hal yang umum yang terjadi dalam sebuah organisasi yang meruapakan sebuah kondisi dinamis dimana seseorang dihadapkan pada konfrontansi antara kesempatan, hambatan atau permintaan, biasanya berupa Simptom yang menjadi bagian penting bagi kehidupan, stres dapat bersifat positif maupun negatif. Pemahaman mengenai stres dapat dilakukan dengan mengetahui dengan indikator: 1 . Penyebab fisik 2. Beban 3.Sifat Pekerjaan 4.Kebebasan 5. Kesulitan .

\section{KERANGKA BERPIKIR}

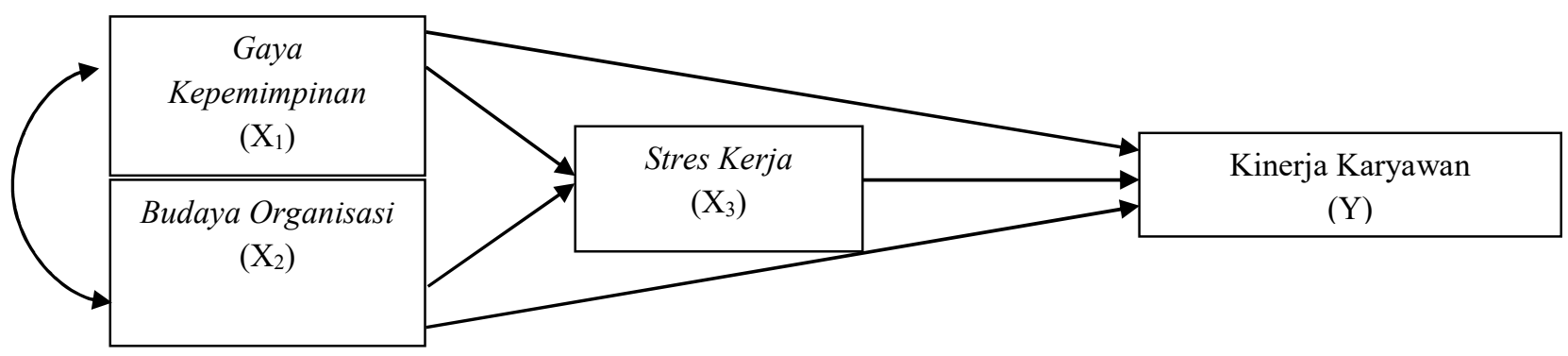


Kerangka berpikir dalam penelitian ini adalah mengungkap dan mengkaji informasi empiric tentang pengaruh langsung dan tidak langsung variabel: Gaya Kepemimpinan $\left(\mathrm{X}_{1}\right)$, Budaya Organisasi $\left(\mathrm{X}_{2}\right)$, Stres Kerja $\left(\mathrm{X}_{3}\right)$ dan Kinerja $(\mathrm{Y})$. Pengaruh antar variabel dapat diuraikan sebagai berikut:

1. Pengaruh Gaya Kepemimpinan terhadap Stres Kerja:

2. Pengaruh Budaya Organisasi terhadap Stres Kerja

3. Pengaruh Gaya Kepemimpinan terhadap Kinerja.

4. Pengaruh Budaya Organisasi terhadap Kinerja.

5. Pengaruh Stres Kerja terhadap Kinerja.

\section{HIPOTESIS PENELITIAN}

Dari uraian di atas diajukan hipotesis yang merupakan jawaban sementara dari pengujian masalah dalam penelitian ini, yaitu:

1. Terdapat Pengaruh Gaya Kepemimpinan terhadap Stres Kerja karyawan social media telkom care.

2. Terdapat pengaruh Budaya Organisasi terhadap Stres Kerja karyawan social media telkom care.

3. Terdapat pengaruh Gaya Kepemimpinan terhadap Kinerja karyawan social media telkom care.
4. Pengaruh Budaya Organisasi terhadap Kinerja karyawan social media telkom care

5. Pengaruh Stres Kerja terhadap Kinerja karyawan social media telkom care.

\section{METODE PENELITIAN}

Metode penelitian yang digunakan dalam penelitian ini adalah metode survei dengan pendekatan kasual. Dalam menganalisis ada tidaknya pengaruh variabel yang lain digunakan analisis jalur atau path analysis. Analisis ini membutuhkan persyaratan hubungan regresional linear yang signifikan antara dua variabel. Untuk menghitung koefisien tiap jalur dibutuhkan koefisien korelasi setiap variabel.

Dengan demikian, untuk menyelesaikan perhitungan koefisien jalur terlebih dahulu harus dilakukan analisis korelasi dan regresi tiap dua variabel. Penelitian ini untuk menganalisis satu variabel terhadap variabel yang lain.

\section{PEMBAHASAN}

1. Model Struktural dan Matriks Korelasi antar Variabel 


\begin{tabular}{|c|c|c|c|c|c|}
\hline \multicolumn{6}{|c|}{$\begin{array}{c}\text { Tabel Matriks Korelasi antar Variabel } \\
\text { Correlations }\end{array}$} \\
\hline & & $\begin{array}{c}\text { GAYA } \\
\text { KEPEMIMPINAN }\end{array}$ & $\begin{array}{l}\text { BUDAYA } \\
\text { ORGANISASI }\end{array}$ & STRES KERJA & KINERJA \\
\hline \multirow[t]{3}{*}{ GAYA KEPEMIMPINAN } & Pearson Correlation & 1 & $.778^{* *}$ & $.698^{* *}$ & $.814^{* *}$ \\
\hline & Sig. (2-tailed) & & .000 & .000 & .000 \\
\hline & $\mathrm{N}$ & 100 & 100 & 100 & 100 \\
\hline \multirow{3}{*}{ BUDAYA ORGANISASI } & Pearson Correlation & $.778^{* *}$ & 1 & $.741^{* *}$ & $.817^{* *}$ \\
\hline & Sig. (2-tailed) & .000 & & .000 & .000 \\
\hline & $\mathrm{N}$ & 100 & 100 & 100 & 100 \\
\hline \multirow[t]{3}{*}{ STRES KERJA } & Pearson Correlation & $.698^{* *}$ & $.741^{* *}$ & 1 & $.792^{* *}$ \\
\hline & Sig. (2-tailed) & .000 & .000 & & .000 \\
\hline & $\mathrm{N}$ & 100 & 100 & 100 & 100 \\
\hline \multirow[t]{3}{*}{ KINERJA } & Pearson Correlation & $.814^{* *}$ & $.817^{* *}$ & $.792^{* *}$ & 1 \\
\hline & Sig. (2-tailed) & .000 & .000 & .000 & \\
\hline & $\mathrm{N}$ & 100 & 100 & 100 & 100 \\
\hline
\end{tabular}

**. Correlation is significant at the 0.01 level (2-tailed).

\begin{tabular}{|l|l|l|}
\hline $\begin{array}{c}\text { Koefisien Korelasi Antar } \\
\text { Variabel }\end{array}$ & \multicolumn{1}{c|}{ Simbol } & Nilai \\
\hline$X_{1}$ dan $X_{2}$ & $r_{12}$ & 0,778 \\
\hline$X_{1}$ dan $X_{3}$ & $r_{13}$ & 0,698 \\
\hline$X_{2}$ dan $X_{3}$ & $r_{23}$ & 0,741 \\
\hline$X_{1} \operatorname{dan} X_{4}$ & $r_{14}$ & 0,814 \\
\hline$X_{2} \operatorname{dan} X_{4}$ & $r_{24}$ & 0,817 \\
\hline$X_{3} \operatorname{dan} X_{4}$ & $r_{34}$ & 0,792 \\
\hline
\end{tabular}

Dari diagram dan tabel jalur tersebut di atas, diperoleh enam buah koefisien jalur, yaitu $\rho_{21}, \rho_{31}, \rho_{32}, \rho_{41}, \rho_{42}$, $\rho_{43}$, dan enam buah koefisien korelasi yaitu $r_{12}, r_{13}, r_{23}, r_{14}, r_{24}, r_{34}$, Sedangkan hasil perhitungan koefisien korelasi yang diperoleh dengan SPSS 24, diperoleh nilai korelasi antar variabel tercantum pada table.

Dari tabel, dapat diketahui bahwa: koefisien korelasi antar variabel $\mathrm{X}_{1}$ dan $\mathrm{X}_{2}$ adalah $\mathrm{r}_{12}=0.778$, koefisien korelasi antar variabel $\mathrm{X}_{1}$ dan $\mathrm{X}_{3}$ adalah $\mathrm{r}_{13}=$ 0.698 , koefisien korelasi antar variabel $\mathrm{X}_{2}$ dan $\mathrm{X}_{3}$ adalah $\mathrm{r}_{23}=0.741$, koefisien korelasi antar variabel $\mathrm{X}_{1}$ dan $\mathrm{Y}$ adalah $\mathrm{r}_{14}=0.814$, koefisien korelasi antar variabel $\mathrm{X}_{2}$ dan $\mathrm{Y}$ adalah $\mathrm{r}_{24}=$ 0.817 , koefisien korelasi antar variabel $\mathrm{X}_{3}$ dan $\mathrm{Y}$ adalah $\mathrm{r}_{34}=0.792$.

2. Perhitungan Koefisien Jalur pada Sub-Struktur

Hubungan kausal antar variabel pada Sub-Struktur-1, dari satu variabel endogen yaitu :

$\mathrm{X}_{3}$ dan dua variabel eksogen yaitu $\mathrm{X}_{1}$, dan $\mathrm{X}_{2}$.

Persamaan struktural untuk substruktur-1 adalah sebagai berikut: $\mathrm{X}_{3}=$ $\rho \mathrm{x}_{3} \mathrm{x}_{1} \mathrm{X}_{1}+\rho \mathrm{x}_{3} \mathrm{x}_{2} \mathrm{X}_{2}+\varepsilon_{1}$. 
Hasil pengolahan data dengan SPSS 24, disajikan pada tabel 3, tabel 4 dan tabel 5., sebagai berikut:

Model 1: Koefisien $X_{1}$, dan $X_{2}$, terhadap $\left(X_{3}\right)$

Tabel Coefficients Model 1 - Sub-Struktur-1

Model Coefficients $^{\mathrm{a}}$

\begin{tabular}{ll|r|r|r|r|r} 
Model & & \multicolumn{2}{c|}{$\begin{array}{c}\text { Unstandardized Coefficients } \\
\text { Coefficients } \\
\text { Beta }\end{array}$} & \multicolumn{1}{c|}{ t } & \multicolumn{1}{c}{ Sig. } \\
\hline 1 & (Constant) & 8.572 & 8.014 & & 1.070 & .287 \\
\cline { 2 - 8 } & GAYA KEPEMIMPINAN & .331 & .113 & .306 & 2.938 & .004 \\
\hline & BUDAYA ORGANISASI & .595 & .123 & .503 & 4.840 & .000 \\
\hline
\end{tabular}

a. Dependent Variable: STRES KERJA

Tabel ANOVA Model 1 - Sub-Struktur-1

ANOVA $^{\mathrm{a}}$

\begin{tabular}{ll|r|r|r|r|r} 
Model & & Sum of Squares & df & Mean Square & \multicolumn{1}{c}{ F } & \multicolumn{1}{c}{ Sig. } \\
\hline 1 & Regression & 9619.847 & 2 & 4809.923 & 68.783 & $.000^{\text {b }}$ \\
\cline { 2 - 7 } & Residual & 6783.143 & 97 & 69.929 & & \\
\cline { 2 - 7 } & Total & 16402.990 & 99 & & & \\
\hline
\end{tabular}

a. Dependent Variable: STRES KERJA

b. Predictors: (Constant), BUDAYA ORGANISASI, GAYA KEPEMIMPINAN

\section{Model 1: Summary $X_{1}$ dan $X_{2}$, terhadap $\left(X_{3}\right)$}

Tabel Model Summary Model 1 - Sub-Struktur-1

\begin{tabular}{|c|c|c|c|c|}
\hline \multicolumn{5}{|c|}{ Model Summary } \\
\hline Model & $\mathrm{R}$ & R Square & $\begin{array}{l}\text { Adjusted R } \\
\text { Square }\end{array}$ & $\begin{array}{l}\text { Std. Error of the } \\
\text { Estimate }\end{array}$ \\
\hline 1 & $.766^{\mathrm{a}}$ & .586 & .578 & 8.36237 \\
\hline
\end{tabular}

Dari tabel 3. dapat dilihat, bahwa: koefisien jalur $\mathrm{X}_{1}$ ke $\mathrm{X}_{3}$ atau $\rho \mathrm{x}_{3} \mathrm{X}_{1}=$ 0.306 , dan koefisien jalur $\mathrm{X}_{2}$ ke $\mathrm{X}_{3}$ atau $\rho \mathrm{x}_{3} \mathrm{X}_{2}=0.503$ Berdasarkan koefisien jalur tersebut, maka persamaan jalur sebagai berikut: $X_{3}=\rho X_{3} X_{1} X_{1}+\rho X_{3} X_{2} X_{2}+\varepsilon_{1}=$ $0.306 \mathrm{X}_{1}+0.503 \mathrm{X}_{2}+\varepsilon_{1}$

Tabel 6 menunjukkan nilai $\mathrm{R}^{2} \mathrm{x}_{3}$ $\left(\mathrm{x}_{1}, \mathrm{x}_{2}\right)=0,586$. sehingga koefisien residu dapat dihitung dengan menggunakan $\operatorname{rumus}_{3} \varepsilon=\sqrt{1-R_{X 3(X 1 X 2)}^{2}}=0,414$ sehingga koefisien residu $\rho \mathrm{X}_{3} \varepsilon=$ $\sqrt{1-0,586}=0,414$ Setelah koefisien jalur diketahui, maka persamaan jalur pada sub - struktur 1 menjadi $\mathrm{X}_{3}=$ $0.306 \mathrm{X}_{1}+0.503 \mathrm{X}_{2}+0,414$

Pengujian keberartian koefisien jalur secara parsial pada Sub Struktur 1 dapat dilakukan dengan melihat tabel 6. Dari hasil perhitungan diperoleh data yang dapat dilihat pada tabel 7 sebagai berikut: 
Tabel Hasil Pengujian Keberatian Koefisien Jalur Sub-Struktur 1

\begin{tabular}{|c|l|l|l|l|}
\hline Jalur & $\begin{array}{l}\text { Koefisien } \\
\text { Jalur }\end{array}$ & thitung & tabel & Hasil Uji \\
\hline$\rho_{31}$ & 0,306 & 2,938 & 1,988 & Signifikan \\
\hline$\rho_{32}$ & 0,503 & 4,840 & 1,988 & Signifikan \\
\hline
\end{tabular}

Dari tabel 4.21 diketahui bahwa nilai hitung Sig. lebih kecil dari pada tingkat $\alpha$ yang digunakan (yaitu 0.05) atau $0.000<0.05$ dan nilai $F_{\text {hitung }}(68,783)$ $>$ Ftabel $(0,324)$. sehingga $\mathrm{H}_{0}$ ditolak , artinya terdapat pengaruh yang berarti atau signifikan antara Gaya Kepemimpinan $\left(\mathrm{X}_{1}\right)$ dan Budaya Organisasi $\left(\mathrm{X}_{2}\right)$ terhadap Stres Kerja $\left(\mathrm{X}_{3}\right)$.

\section{Perhitungan Besar Pengaruh pada}

\section{Sub-Struktur 1}

Untuk mengetahui besarnya pengaruh yang diterima oleh sebuah variabel endogen dari dua variabel eksogen, dapat secara parsial maupun bersama-sama. Pengaruh secara parsial berupa pengaruh langsung, maupun pengaruh tidak langsung, yaitu melalui variabel eksogen yang lain.

a. Menghitung pengaruh langsung, pengaruh tidak langsung, serta pengaruh total variabel Gaya Kepemimpinan $\left(\mathrm{X}_{1}\right)$ terhadap variabel Stres Kerja $\left(\mathrm{X}_{3}\right)$ secara parsial bersama variabel Budaya Organisasi $\left(\mathrm{X}_{2}\right)$ :

1) Besarnya pengaruh langsung variabel $\left(\mathrm{X}_{1}\right)$ terhadap variabel $\left(\mathrm{X}_{3}\right)=\rho \mathrm{x}_{3} \mathrm{x}_{1} \mathrm{x} \rho \mathrm{x}_{3} \mathrm{x}_{1}=0.306 \mathrm{x}$ $0.306=0.0936=9,36 \%$
2) Besarnya pengaruh tidak langsung variabel Gaya Kepemimpinan $\left(\mathrm{X}_{1}\right)$ terhadap variabel Stres Kerja $\left(\mathrm{X}_{3}\right)$, melalui variabel Budaya Organisasi $\left(\mathrm{X}_{2}\right)$ $=\rho \mathrm{x}_{3} \mathrm{x}_{1} \mathrm{x} \quad \mathrm{rx}_{1} \mathrm{x}_{2} \mathrm{x} \rho \mathrm{x}_{3} \mathrm{x}_{2}=0.306 \mathrm{x}$ $0.578 \times 0.503=0.089=8,9 \%$

3) Besarnya pengaruh total variabel $X_{1}$ terhadap variabel $X_{3}$ melalui variabel $\mathrm{X}_{2},=\left[\rho \mathrm{x}_{3} \mathrm{X}_{1} \mathrm{x}_{\rho} \rho \mathrm{x}_{3} \mathrm{X}_{1}\right]+$ $\left[\rho \mathrm{x}_{3} \mathrm{x}_{1} \mathrm{xrX}_{1} \mathrm{X}_{2} \mathrm{X}_{\mathrm{N}} \mathrm{x}_{3} \mathrm{x}_{2}\right]=0.0936+$ $0.089=0.1826=18,26 \%$

Kesimpulan : pengaruh variabel Gaya Kepemimpinan $\left(\mathrm{X}_{1}\right)$ terhadap variabel Stres Kerja $\left(\mathrm{X}_{3}\right)$ adalah sebesar $18,26 \%$, hal ini berarti Stres Kerja ditentukan oleh Gaya Kepemimpinan sebesar 18,26\%.

b. Menghitung pengaruh langsung, pengaruh tidak langsung, serta pengaruh total variabel Budaya Organisasi $\left(\mathrm{X}_{2}\right)$ terhadap variabel Stres Kerja $\left(\mathrm{X}_{3}\right)$ secara parsial bersama variabel Gaya Kepemimpinan $\left(\mathrm{X}_{1}\right)$ :

1) Besarnya pengaruh langsung variabel $\left(\mathrm{X}_{2}\right)$ terhadap variabel $\left(X_{3}\right)=\rho x_{3} x_{2} x \rho x_{3} x_{2}=0.503 x$ $0.503=0.2530=25,30 \%$

2) Besarnya pengaruh tidak langsung variabel $\left(\mathrm{X}_{2}\right)$ terhadap 
variabel $\left(\mathrm{X}_{3}\right)$, melalui variabel

Gaya Kepemimpinan $\left(\mathrm{X}_{1}\right)$

$=\rho \mathrm{x}_{3} \mathrm{x}_{2} \mathrm{x}_{\mathrm{r}} \mathrm{x}_{1} \mathrm{x}_{2} \mathrm{x}_{\rho} \mathrm{x}_{3} \mathrm{x}_{1}=0.503 \mathrm{x}$ $0.586 \times 0.306=0.0901=9,01 \%$

3) Besarnya pengaruh total variabel $\mathrm{X}_{2}$ terhadap variabel $\mathrm{X}_{3}$ melalui variabel Gaya Kepemimpinan $\left(\mathrm{X}_{1}\right), \quad=$ $\left[\rho \mathrm{x}_{3} \mathrm{X}_{2} \mathrm{x}_{\rho} \mathrm{x}_{3} \mathrm{X}_{2}\right]$

$\left[\rho \mathrm{x}_{3} \mathrm{x}_{2} \mathrm{xrx}_{1} \mathrm{x}_{2} \mathrm{x}_{\mathrm{N}} \mathrm{x}_{3} \mathrm{x}_{1}\right]=0,2530+$ $0,0901=0,3431=34,31 \%$

Kesimpulan : pengaruh variabel Budaya Organisasi $\left(\mathrm{X}_{2}\right)$ terhadap variabel Stres
Kerja $\left(\mathrm{X}_{3}\right)$ adalah sebesar $34,31 \%$, hal ini berarti Budaya Organisasi ditentukan oleh Stres Kerja sebesar 34,31\%.

4. Perhitungan Koefisien Jalur pada

\section{Sub-Struktur-2}

Persamaan struktural sub-struktur-2 adalah :

$Y=\rho Y_{1} X_{1}+\rho Y x_{2} X_{2}+\rho Y x_{3} X_{3}+\varepsilon_{3}$.

Hasil pengolahan data dengan SPSS 24, sesuai tabel berikut ini:

\section{Model 1: Koefisien $X_{1}, X_{2}$,dan $X_{3}$ terhadap Kinerja (Y)}

Tabel Coefficients Model 1 - Sub-Struktur-2

\begin{tabular}{|c|c|c|c|c|c|c|}
\hline \multicolumn{7}{|c|}{ Coefficients ${ }^{\mathrm{a}}$} \\
\hline \multirow{2}{*}{\multicolumn{2}{|c|}{ Model }} & \multicolumn{2}{|c|}{ Unstandardized Coefficients } & \multirow{2}{*}{$\begin{array}{c}\text { Standardized } \\
\text { Coefficients } \\
\text { Beta }\end{array}$} & \multirow[b]{2}{*}{$\mathrm{t}$} & \multirow[b]{2}{*}{ Sig. } \\
\hline & & B & Std. Error & & & \\
\hline \multirow[t]{4}{*}{1} & (Constant) & -11.439 & 6.131 & & -1.866 & .065 \\
\hline & GAYA KEPEMIMPINAN & .406 & .089 & .354 & 4.547 & .000 \\
\hline & BUDAYA ORGANISASI & .382 & .104 & .305 & 3.667 & .000 \\
\hline & STRES KERJA & .337 & .077 & .318 & 4.370 & .000 \\
\hline
\end{tabular}

Model 1: ANOVA $X_{1}, X_{2}$, dan $X_{3}$ terhadap Kinerja (Y)

Tabel ANOVA Model 1 - Sub-Struktur-2

\begin{tabular}{|c|c|c|c|c|c|c|}
\hline \multirow[b]{2}{*}{ Model } & & \multicolumn{3}{|c|}{ ANOVA $^{a}$} & \multirow[b]{2}{*}{$\mathrm{F}$} & \multirow[b]{2}{*}{ Sig. } \\
\hline & & Sum of Squares & df & Mean Square & & \\
\hline 1 & Regression & 14544.084 & 3 & 4848.028 & 119.862 & $.000^{\mathrm{b}}$ \\
\hline & Residual & 3882.876 & 96 & 40.447 & & \\
\hline & Total & 18426.960 & 99 & & & \\
\hline
\end{tabular}

\section{Model 1: Summary $X_{1}, X_{2}$, dan $X_{3}$, terhadap Kinerja (Y)}

Tabel Model Summary Model 1 - Sub-Struktur-2 Model Summary

\begin{tabular}{lr|rr|r} 
Model & $\mathrm{R}$ & R Square & Adjusted R Square & \multicolumn{2}{c}{ Std. Error of the Estimate } \\
\hline 1 & $.888^{\mathrm{a}}$ & .789 & .783 & \\
\hline a. Predictors: (Constant), STRES KERJA, GAYA KEPEMIMPINAN, BUDAYA ORGANISASI
\end{tabular}

Dari tabel 4.10. diketahui, bahwa: koefisien jalur $\mathrm{X}_{1}$ ke $\mathrm{Y}$ atau $\rho \mathrm{Yx}_{1}=$
0.354 , koefisien jalur $\mathrm{X}_{2}$ ke $\mathrm{Y}$ atau $\rho \mathrm{Yx}_{2}$ $=0.305$, koefisien jalur $\mathrm{X}_{3}$ ke $\mathrm{Y}$ atau 
$\rho \mathrm{Yx}_{3}=0.318$. Menurut koefisien jalur, maka persamaan jalur, adalah: $\mathrm{Y}=$ $\rho \mathrm{Yx}_{1} \mathrm{X}_{1}+\rho \mathrm{Yx}_{2} \mathrm{X}_{2}+\rho \mathrm{Yx}_{3} \mathrm{X}_{3}+\varepsilon_{2}$

$Y=0.354 X_{1}+0.305 X_{2}+0.318 X_{3}+\varepsilon_{2}$

Tabel 4.20 menunjukkan nilai $\mathrm{R}^{2}$ $\mathrm{x}_{3}\left(\mathrm{x}_{1}, \mathrm{x}_{2}\right)=0,846$. sehingga koefisien residu dapat dihitung dengan menggunakan rumus $3 \quad \varepsilon={ }_{3} \quad \varepsilon=$ $\sqrt{1-R_{X 3(X 1 X 2)}^{2}} \quad=0,211 \quad$ sehingga koefisien residu $\quad \rho \quad \mathrm{X}_{3} \quad \varepsilon=$ $\sqrt{1-0,789}=0,211$ Setelah koefisien jalur diketahui , maka persamaan jalur pada sub - struktur 1 menjadi $\mathrm{X}_{3}=$ $00.354 \mathrm{X}_{1}+0.305 \mathrm{X}_{2}+0.318 \mathrm{X}_{3}+0,211$

$$
\text { Pengujian keberartian }
$$

koefisien jalur secara parsial pada SubStruktur 1 dapat dilakukam dengan melihat tabel 7. Dari hasil perhitungan diperoleh data yang dapat dilihat pada tabel 10 sebagai berikut:

Tabel Hasil Pengujian Keberatian Koefisien Jalur Sub-Struktur 1

\begin{tabular}{|c|c|c|c|c|}
\hline Jalur & $\begin{array}{c}\text { Koefisien } \\
\text { Jalur }\end{array}$ & $\mathbf{t}_{\text {hitung }}$ & $\mathbf{t}_{\text {tabel }}$ & Hasil Uji \\
\hline$\rho_{41}$ & 0,354 & 4,547 & 1,988 & Signifikan \\
\hline$\rho_{42}$ & 0,305 & 3,667 & 1,988 & Signifikan \\
\hline$\rho_{43}$ & 0,318 & 4,370 & 1,988 & Signifikan \\
\hline
\end{tabular}

Dari tabel 12 diketahui bahwa nilai hitung Sig. lebih kecil dari pada tingkat $\alpha$ yang digunakan (yaitu 0.05 ) atau $0.000<$ 0.05 dan nilai $F_{\text {hitung }}(119,862)>F_{\text {tabel }}$ (2,717). sehingga $\mathrm{H}_{0}$ ditolak , artinya terdapat pengaruh yang berarti atau signifikan antara Gaya Kepemimpinan $\left(\mathrm{X}_{1}\right)$, Budaya Organisasi $\left(\mathrm{X}_{2}\right)$, Stres Kerja $\left(\mathrm{X}_{3}\right)$ terhadap Kinerja $(\mathrm{Y})$.

\section{Perhitungan Besar Pengaruh pada Sub}

\section{- Struktur 2}

Untuk mengetahui besarnya pengaruh yang diterima oleh sebuah Variabel endogen dari dua buah variabel endogen. dapat secara parsial (langsung maupun tidak langsung melalui varibel eksogen lain ) maupun secara bersama sama

a. menghitung pengaruh langsung pengaruh tidak langsung serta pengaruh total variabel Gaya Kepemimpinan $\left(\mathrm{X}_{1}\right)$, terhadap variabel Kinerja (Y) secara parsial, sebagai berikut:

1) besarnya pengaruh langsung variabel $\mathrm{X}_{1}$ terhadap variabel $\mathrm{Y}$ $=\rho_{\mathrm{YX}_{1}} \mathrm{x} \rho \mathrm{YX}_{1}=(0,354)^{2}=0,1253$

2) besarnya pengaruh tidak langsung variabel $\mathrm{X}_{1}$ terhadap variabel $\mathrm{Y}$ melalui $\mathrm{X}_{2}$

$=\rho \mathrm{Yx}_{1} \mathrm{x} \quad \mathrm{rx}_{1} \mathrm{x}_{2} \mathrm{x} \rho \mathrm{Yx}_{2}=0,354 \mathrm{x}$ $0,789 \times 0,305=0,085$ 
3) besarnya pengaruh tidak langsung variabel $\mathrm{X}_{1}$ terhadap variabel $\mathrm{Y}$ melalui $\mathrm{X}_{3}$

$=\rho_{\mathrm{YX}} \mathrm{X}_{1} \mathrm{rx}_{1} \mathrm{X}_{3} \mathrm{x} \rho \mathrm{Yx}_{3}=0,354 \mathrm{x} 0,789$

$$
\mathrm{x} 0,318=0,089
$$

4) besarnya pengaruh total variabel $\mathrm{X}_{1}$ terhadap variabel $\mathrm{X}_{3}$

$$
\begin{aligned}
& =\quad\left[\rho \mathrm{Yx}_{1} \mathrm{x} \rho \mathrm{Yx}_{1}\right] \\
& {\left[\rho \mathrm{Yx}_{1} \mathrm{xrx}_{1} \mathrm{x}_{2} \mathrm{x} \rho \mathrm{Yx}_{2}\right]} \\
& {\left[\rho \mathrm{Yx}_{1} \mathrm{xrx}_{1} \mathrm{x}_{3} \mathrm{x} \rho \mathrm{Yx}_{3}\right]=0 .} \\
& 0.0829+0.1044=0,125+0,085+ \\
& 0,089=0,299
\end{aligned}
$$

Kesimpulannya pengaruh variabel Gaya Kepemimpinan $\left(\mathrm{X}_{1}\right)$ terhadap variabel Kinerja (Y) adalah sebesar 0,299 hal ini berarti Kinerja ditentukan oleh Kepemimpinan sebesar 0,299

b. Menghitung pengaruh langsung pengaruh tidak langsung serta pengaruh total variabel Budaya Organisasi $\left(\mathrm{X}_{2}\right)$ terhadap variabel Kinerja $(\mathrm{Y})$ secara parsial, sebagai berikut:

1) besarnya pengaruh langsung variabel $\mathrm{X}_{2}$ terhadap variabel $\mathrm{Y}$ $=\rho Y x_{2} x \rho x_{2}=(0,305)^{2}=0,093$

2) besarnya pengaruh tidak langsung variabel $\mathrm{X}_{2}$ terhadap variabel $\mathrm{Y}$ melalui $\mathrm{X}_{1}$

$=\rho \mathrm{Yx}_{2} \mathrm{x}_{\mathrm{rx}} \mathrm{rx}_{1} \mathrm{x}_{2} \mathrm{x} \rho \mathrm{Y} \mathrm{x}_{1}=0,305 \mathrm{x}$ $0,789 \times 0,354=0,085$

3) besarnya pengaruh tidak langsung variabel $\mathrm{X}_{2}$ terhadap variabel $\mathrm{Y}$ melalui $\mathrm{X}_{3}$ $=\rho \mathrm{Yx}_{2} \mathrm{x} \quad \mathrm{rx}_{2} \mathrm{x}_{3} \mathrm{x} \rho \mathrm{Yx}_{3}=0,305 \mathrm{x}$

$0,789 \times 0,318=0,076$

4) besarnya pengaruh total variabel $\mathrm{X}_{1}$ terhadap variabel $\mathrm{X}_{3}$

$=\left[\rho \mathrm{Yx}_{2} \mathrm{x} \rho \mathrm{Yx}_{2}\right]+\left[\rho \mathrm{Yx}_{2} \mathrm{x}\right.$ $\left.\mathrm{rx}_{1} \mathrm{x}_{2} \mathrm{x} \rho \mathrm{Yx}_{1}\right]+\left[\rho \mathrm{Yx}_{2} \mathrm{x}_{\mathrm{rx}} \mathrm{x}_{2} \mathrm{x}_{3} \mathrm{x} \rho \mathrm{Yx}_{3}\right]$ $=0,093+0,085+0,076=0,254$

Kesimpulannya pengaruh variabel Budaya Organisasi $\left(\mathrm{X}_{2}\right)$ terhadap variabel Kinerja (Y) adalah sebesar 0,254 hal ini berarti Kinerja ditentukan oleh Budaya Organisasi sebesar 0,254

c. Menghitung pengaruh langsung pengaruh tidak langsung serta pengaruh total variabel Stres Kerja $\left(\mathrm{X}_{3}\right)$ terhadap variabel Kinerja $(\mathrm{Y})$ secara parsial, sebagai berikut:

1) besarnya pengaruh langsung variabel $\mathrm{X}_{3}$ terhadap variabel $\mathrm{Y}$ $=\rho \mathrm{Yx}_{3} \times \rho \mathrm{Yx}_{3}=(0,318)^{2}=0,101$

2) besarnya pengaruh tidak langsung variabel $\mathrm{X}_{3}$ terhadap variabel $\mathrm{Y}$ melalui $\mathrm{X}_{1}$

$=\rho \mathrm{Yx}_{3} \mathrm{x} \quad \mathrm{rx}_{1} \mathrm{x}_{3} \mathrm{x} \rho \mathrm{Yx}_{1}=0,318 \mathrm{x}$ $0,789 \times 0,354=0,088$

3) besarnya pengaruh tidak langsung variabel $\mathrm{X}_{2}$ terhadap variabel $\mathrm{Y}$ melalui $\mathrm{X}_{3}$

$=\rho \mathrm{Yx}_{3} \mathrm{x} \quad \mathrm{rx}_{2} \mathrm{x}_{3} \mathrm{x} \rho \mathrm{Yx}_{2}=0,318 \mathrm{x}$

$$
0,789 \times 0,305=0,076
$$

4) besarnya pengaruh total variabel $\mathrm{X}_{3}$ terhadap variabel $\mathrm{Y}$

$=\left[\begin{array}{lll}\rho Y x_{3} & x & \rho Y x_{3}\end{array}\right]+\left[\rho Y x_{3} x\right.$ $\left.\operatorname{rx}_{1} \mathrm{x}_{3} \mathrm{x} \rho Y \mathrm{x}_{1}\right]+\left[\rho \mathrm{Yx}_{3} \mathrm{x} \mathrm{rx}_{2} \mathrm{x}_{3} \mathrm{x} \rho \mathrm{Y} \mathrm{x}_{2}\right]$ 


$$
=0,101+0,088+0,076=0,265
$$

Kesimpulannya pengaruh variabel Stres Kerja $\left(\mathrm{X}_{3}\right)$ terhadap variabel Kinerja (Y) adalah sebesar 0,265 hal ini berarti Kinerja ditentukan oleh Stres Kerja sebesar 0,265.

\section{PENGUJIAN HIPOTESIS}

Berdasarkan perhitungan statistik yang telah dilakukan, maka hasil perhitungan yang diperoleh digunakan untuk menguji hipotesis yang diajukan. penarikan kesimpulan hipotesis dilakukan melalui nilai $\mathrm{t}$ dengan menentukan besarnya $t_{\text {hitung. jika nilai } t_{\text {hitung }}<}$ $t_{\text {tabel, }}$ maka $\mathrm{H}_{0}$ diterima dan $\mathrm{H}_{1}$ ditolak, artinya tidak ada pengaruh. jika nilai $t_{\text {hitung }}>t_{\text {tabel, }}$ maka $\mathrm{H}_{0}$ ditolak dan $\mathrm{H}_{1}$ diiterima, artinya ada pengaruh. hasil penelitian berdasarkan hipotesis yang diajukan akan diuraikan dengan beberapa pernyataan sebagai berikut :

Tabel Rekapitulasi Hasil Pengujian Hipotesis

\begin{tabular}{|c|c|c|c|c|}
\hline No. & Hipotesis & Uji Statistik & Keputusan & Kesimpulan \\
\hline 1. & 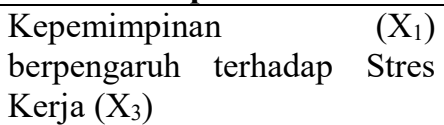 & $\begin{array}{l}\mathrm{H}_{0}: \rho_{31}=0 \\
\mathrm{H}_{1}: \rho_{31}>0\end{array}$ & $\mathrm{H}_{0}$ ditolak & $\begin{array}{l}\text { Mempunyai } \\
\text { pengaruh positif }\end{array}$ \\
\hline 2 & 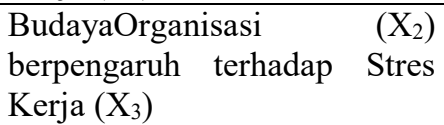 & $\begin{array}{l}\mathrm{H}_{0}: \rho_{32}=0 \\
\mathrm{H}_{1}: \rho_{32}>0\end{array}$ & $\mathrm{H}_{0}$ ditolak & $\begin{array}{l}\text { Mempunyai } \\
\text { pengaruh positif }\end{array}$ \\
\hline 3 & $\begin{array}{l}\text { Kepemimpinan }\left(\mathrm{X}_{1}\right) \\
\text { berpengaruh terhadap Kinerja } \\
(\mathrm{Y})\end{array}$ & $\begin{array}{l}\mathrm{H}_{0}: \rho_{41}=0 \\
\mathrm{H}_{1}: \rho_{41}>0\end{array}$ & $\mathrm{H}_{0}$ ditolak & $\begin{array}{l}\text { Mempunyai } \\
\text { pengaruh positif }\end{array}$ \\
\hline 4 & $\begin{array}{l}\text { BudayaOrganisasi }\left(\mathrm{X}_{2}\right) \\
\text { berpengaruh terhadap Kinerja } \\
(\mathrm{Y})\end{array}$ & $\begin{array}{l}\mathrm{H}_{0}: \rho_{42}=0 \\
\mathrm{H}_{1}: \rho_{42}>0\end{array}$ & $\mathrm{H}_{0}$ ditolak & $\begin{array}{l}\text { Mempunyai } \\
\text { pengaruh positif }\end{array}$ \\
\hline 5 & $\begin{array}{l}\text { Stres Kerja }\left(\mathrm{X}_{3}\right) \text { berpengaruh } \\
\text { terhadap Stres Kerja }(\mathrm{Y})\end{array}$ & $\begin{array}{l}\mathrm{H}_{0}: \rho_{43}=0 \\
\mathrm{H}_{1}: \rho_{43}>0\end{array}$ & $\mathrm{H}_{0}$ ditolak & $\begin{array}{l}\text { Mempunyai } \\
\text { pengaruh positif }\end{array}$ \\
\hline
\end{tabular}

\section{KESIMPULAN}

Berdasarkan hasil analisis data dan pembahasan hasil penelitian, maka temuan penelitian dapat disimpulkan sebagai berikut :

\section{Terdapat pengaruh Langsung Gaya} Kepemimpinan terhadap Stres Kerja Karyawan Layanan Social Media Telkom Care PT. Telkom Indonesia. Temuan ini dapat di artikan bahwa tinggi rendahnya Stres Kerja salah satu faktornya dipengaruhi Gaya Kepemimpinan, sehingga jika Gaya
Kepemimpinan ditingkatkan, maka stres kerja akan menurun.

2. Terdapat pengaruh Langsung Budaya Organisasi terhadap Stres Kerja Karyawan Layanan Social Media Telkom Care PT. Telkom Indonesia. Temuan ini dapat di artikan bahwa tinggi rendahnya Stres Kerja salah satu faktornya dipengaruhi oleh Budaya Organisasi, sehingga jika Budaya organisasi ditingkatkan, dapat menurunkan Stres Kerja. 
3. Terdapat pengaruh Langsung Gaya Kepemimpinan terhadap Kinerja Karyawan Layanan Social Media Telkom Care PT. Telkom Indonesia. Temuan ini dapat di artikan bahwa tinggi rendahnya Kinerja salah satu faktornya dipengaruhi oleh Gaya Kepemimpinan, sehingga jika Gaya Kepemimpinan ditingkatkan, maka dapat meningkatakan Kinerja.

4. Terdapat pengaruh Langsung Budaya Organisasi terhadap Kinerja Karyawan Layanan Social Media Telkom Care PT. Telkom Indonesia. Temuan ini dapat di artikan bahwa tinggi rendahnya Kinerja salah satu faktornya dipengaruhi oleh Budaya Organisasi, sehingga jika Budaya Organisasi ditingkatkan, dapat meningkatakan Kinerja.

5. Terdapat pengaruh Langsung Stres Kerja terhadap Kinerja Karyawan Layanan Social Media Telkom Care PT. Telkom Indonesia. Temuan ini dapat di artikan bahwa tinggi rendahnya Kinerja salah satu faktornya dipengaruhi oleh Stres Kerja, sehingga jika Stres Kerja meningkat maka dapat menurunkan Kinerja.

\section{SARAN}

Berdasarkan kesimpulan hasil peneltian di atas, maka diajukan saran hasil penelitian sebagai berikut :

1. Untuk meningkatkan Kinerja, Gaya Kepemimpinan Karyawan Layanan Social Media Telkom Care PT. Telkom Indonesia, diperlukan meningkatkan peranan pemimpin baik bersifat interpersonal, informasional, maupun sebagai pengambil keputusan.

2. Untuk meningkatkan Kinerja, Budaya Organisasi di Layanan Social Media Telkom Care PT. Telkom Indonesia, diperlukan pemimpin yang mengetahui bagaimana teknik pengerjaan, mengetahui kendalakendala yang dihadapi, turun langsung kelapangan, tujuannya agar menciptakan hubungan baik antar atasan dengan karyawan dan memahami bagaimana tingkat kesulitan dari setiap proses agar dapat menemukan teknik agar produktivitas bisa berjalan dengan baik.

3. Untuk meningkatkan Kinerja, Stres Kerja Karyawan Layanan Social Media Telkom Care PT. Telkom Indonesia perlu di minimalisir melalui pemberian Reward dan punishment efektif untuk mempertahankan karyawan berkualitas. Jika seorang karyawan kinerjanya unggul atau menghasilkan profit besar bagi perusahaan, tidak ada salahnya diberi penghargaan. Penghargaan bisa berupa jalan-jalan baik ke luar negeri ataupun dalam negeri, bonus berupa uang, atau perhiasan. Namun ada kalanya penghargaan tidak berupa hadiah yang mahal. Misalnya berikan satu hari off atau kue jika karyawan Anda mencapai target atau memberikan keuntungan bagi perusahaan.

4. Penambahan skill karyawan seiring dengan perkembangan ilmu pengetahuan dan teknologi. Maka mengadakan training dan 
pelatihan perlu dilakukan untuk meningkatkan kinerja dan motivasi kerja karyawan. Training dan pelatihan ini diharapkan dapat menyegarkan dan menambah cakrawala berpikir para karyawan dan pemberian Jenjang karier sesuai masa kerja atau prestasi karena jenjang karir erat kaitannya dengan motivasi kerja.

\section{DAFTAR PUSTAKA.}

Ardana, Komang, Ni Wayan Mujiati, I Wayan Mudiartha Utama. Manajemen Sumber Daya Manusia. Yogyakarta : Graha Ilmu. 2012.

Danang, Sunyoto dan Burhanudin. Perilaku Organisasi. Yogyakarta : Penerbit CAPS. 2011

Danang, Sunyoto. Penelitian Sumber Daya Manusia. Jakarta: PT Buku Seru. 2015.

Effendy, Onong Uchjana. Hubungan Masyarakat Suatu Studi Komunikologis. Bandung : Remaja Rosdakarya. 2002

Foster, Bill dan Karen R. Seeker. Pembinaan Untuk Meningkatkan Kinerja Karyawan. Jakarta : PT.Toko Gunung Agung Tbk, 2001.

H. Hadari Nawawi. Kepemimpinan Mengefektifkan Organisasi. Yogyakarta: UGM Press, 2003.

Hasibuan, Malayu S.P. Manajemen Sumber Daya Manusia. Jakarta. Penerbit PT Bumi Aksara. 2007.

Organisasi dan Motivasi. Jakarta: Bumi Aksara. 2003

Husein, Umar. Metode Riset Bisnis. PT. Gramedia Pustaka Utama. Jakarta. 2002
Ishak dan Hendri Tanjung. Manajemen Motivasi. Jakarta: PT. Grasindo, 2003.

Jason A. Colquitt, Jeffery A. Lepine, Michael Wesson. Organizational Behaviour, Edition II, ed. New York: McGraw-Hill, 2011.

Knicki and Keitner. Organization Behaviour. McGraw-Hill International Edition, 2008.

Liliweri, Alo. Makna Budaya dalam Komunikasi Antar Budaya. Yogjakarta: Lkis Yogjakarta, 2002.

Mangkunegara, Anwar Prabu, Manajemen Sumber Daya Manusia Perusahaan. Bandung: Remaja Rosdakarya. 2009.

Muhammad, Ami. Komunikasi Organisasi Cetakan Kedua belas. Jakarta: Bumi Aksara, 2011.

Mulyana, Deddy Ilmu Komunikasi Suatu Pengantar, Bandung: PT Remaja Rosdakarya. 2010

Pengantar, Bandung: PT Remaja Rosdakarya. 2005

Nawawi, H. Hadari. Kepemimpinan Mengefektifkan Organisasi. Yogyakarta: UGM Press. 2003

Rahardi, Dedy Rianto. Manajemen Penelitian dan Evaluasi Kinerja Sumber Daya Manusia. Malang: Tunggal Mandiri Publishing, 2010.

Rivai, Veithzal. Kepemimpinan dan Perilaku Organisasi. Jakarta : Rajawali Pers. 2003.

Rivai, Vithzal dan Dato Achmat Fawzi, Performace Appraisal. Jakarta: PT Raja Grafindo Persana, 2005.

Rohim, Syaiful, Teori Komunikasi Prespektif, Ragam, dan Aplikasi, Jakarta: PT Rineka Cipta. 2009 
Simamora. Manajemen Sumber Daya Manusia, Cetakan 3, STIE. YKPN, Yogyakarta. 2005

Soemanto, Wasty. Psikologi Pendidikan. Jakarta: PT Rineka Cipta, 2006.

Sofyandi dan Garniwa. Perilaku Organisasional Edisi Pertama. Yogyakarta: Graha Ilmu, 2007.

Sondang, Siagian. Manajemen Sumber Daya Manusia. Jakarta: Bumi Akasara. 2015.

Robbin, Stephen P, dan Timothy A Judge. Perilaku Organisasi. Jakarta: Salemba empat. 2008.

Vancevich, John M., dkk. Perilaku dan Manajemen Organisasi, Edisi Ketujuh, Jilid2, Jakarta: Erlangga, 2007.

Wardiah, Mia Lasmi. Teori Perilaku dan budaya organisasi. Jakarta: CV Pustaska Setia. 2016

Wiryanto. Pengantar Ilmu Komunikasi. Jakarta: PT Grasindo, 2004 